\title{
15-Membered triolefinic macrocycles, their coordination chemistry with transition metals, and the catalytic properties of their palladium metal complexes. A review
}

\author{
Marcial Moreno-Mañas, ${ }^{a}$ Roser Pleixats, ${ }^{a}$ Anna Roglans, ${ }^{b}$ \\ Rosa M. Sebastián, ${ }^{a}$ and Adelina Vallribera ${ }^{a}$ \\ ${ }^{a}$ Department of Chemistry, Universitat Autònoma de Barcelona, Cerdanyola, 08193-Barcelona, \\ Spain \\ ${ }^{b}$ Department of Chemistry, Universitat de Girona, 17071-Girona, Spain \\ E-mail: marcial.moreno@uab.es
}

\section{Dedicated to Professor Enrique Meléndez on occasion of his retirement}

(received 06 Sep 03; accepted 12 Jan 04; published on the web 22 Jan 04)

\begin{abstract}
(E,E,E)-1,6,11-Tris(arenesulfonyl)-1,6,11-triazacyclopentadeca-3,8,11-trienes, 1, are prepared from arenesulfonamides and trans-1,4-dibromo-2-butene. Macrocycles $\mathbf{1}$ coordinate palladium(0), platinum(0), and silver(I), and the palladium complexes are useful and reutilizable catalysts or precatalysts in Suzuki cross-couplings, butadiene telomerizations, hydroarylation of alkynes, and in the Heck reaction. Structurally related macrocycles are also available by similar synthetic procedures.
\end{abstract}

Keywords: Alkene ligands, macrocycles, heterocycles, olefin complexes, catalysis

\section{Contents}

1. Introduction

2. Preparation of compounds

2.1 Preparation of 15-membered macrocycles

2.2 Preparation of metal complexes

3. Structure and spectroscopy

4. Catalysis

5. Related macrocycles

6. Concluding remarks 


\section{Introduction}

Nitrogen-containing 15-membered macrocycles with endocyclic olefins are uncommon. ${ }^{1} \mathrm{~A}$ few nitrogen-containing monoolefinic 15 -membered rings have been prepared by metathesis. ${ }^{2}$

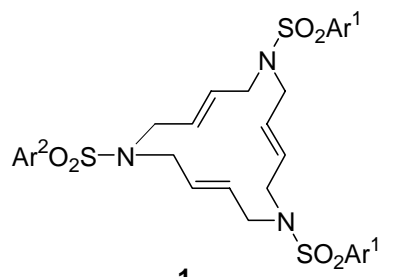

1

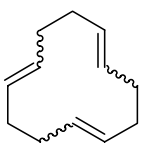

2

Figure 1. General Structure of macrocycles 1 and 2.

Macrocycles 1 (Figure 1) are structurally related to the 12-membered carbocyclic cyclododeca-1,5,9-trienes, 2 . Cyclotrienes 2 coordinate nickel(0) and are formed by trimerization of butadiene. The nickel complexes of $\mathbf{2}$ have played a fundamental role in catalysis and in organonickel chemistry. $^{3}$

We discovered macrocycles $\mathbf{1}$ in a serendipitous manner when exploring the palladiumcatalyzed reaction of arenesulfonamides with 2-butene-1,4-diol biscarbonate (Scheme 1). ${ }^{4} 10$-, 15-, and 20-membered cycles were isolated and identified. One part of the 15-membered rings appeared in the form of their palladium(0) complexes 4 (vide infra). Due to the similarity of IR and NMR data of 15- and 20-membered macrocyles, MALDI-TOF mass spectrometry was fundamental in the identification of the products. ${ }^{5}$
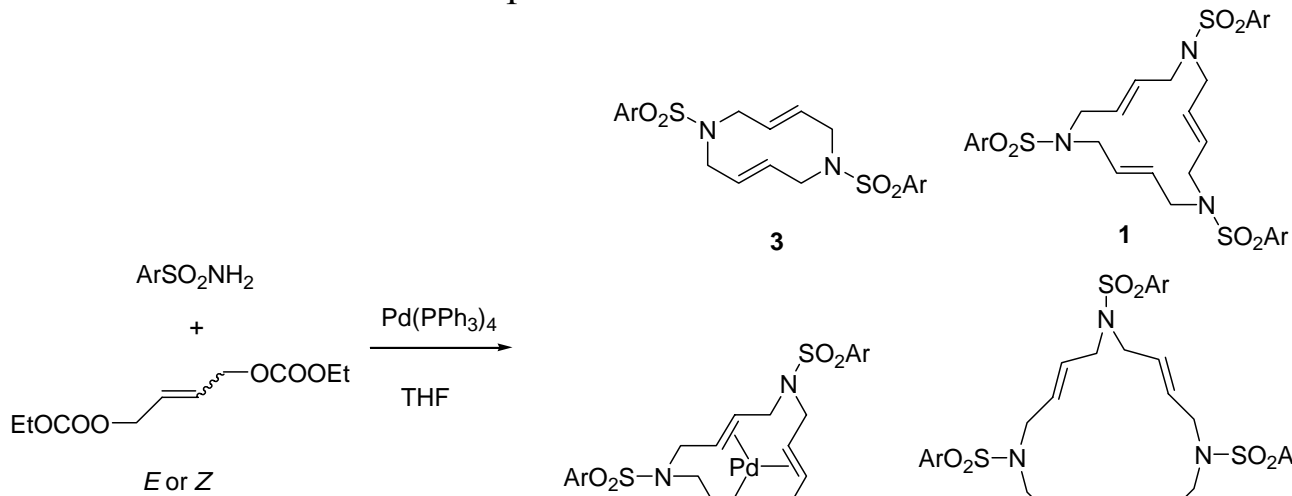

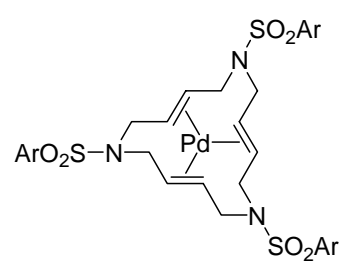

4

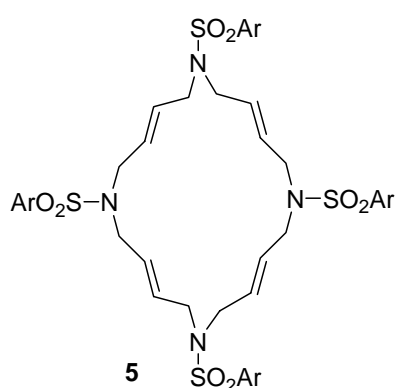

Scheme 1. Formation of medium and large cycles in a palladium catalyzed Tsuji-Trost reaction ${ }^{4}$. 
We soon noticed that we had a new chemistry in our hands. Indeed, the three olefinic double bonds are excellent coordinating centers for some transition metals. Moreover, the nitrogen atoms are devoid of coordinating ability due to lone pair conjugation with the $\mathrm{SO}_{2}$ group, therefore leaving all coordination capacity to the three olefins.

Moreover, a broad array of arenesulfonamides or their immediate precursors arenesulfonyl chlorides are commercially available. Therefore, other properties of the macrocycles can be tuned by introducing arene or heteroarene groups that improve or impart solubility, crystallinity, electrochemical properties, polymerization ability, certain types of reactivity, etcetera. Since preparation of 1 involves the use of trans-1,4-dibromo-2-butene, different structurally related macrocycles can be built up by working with, for example, cis-1,4-dibromo-2-butene or 1,2bis(bromomethyl)benzene.

\section{Preparation of compounds}

\subsection{Preparation of 15-membered macrocycles}

Our group described in 1998 the first 15-membered triolefinc macrocycles $1{ }^{4}$ Since then, a broad array of compounds 1 had been prepared (Table 1 and Figure 2).
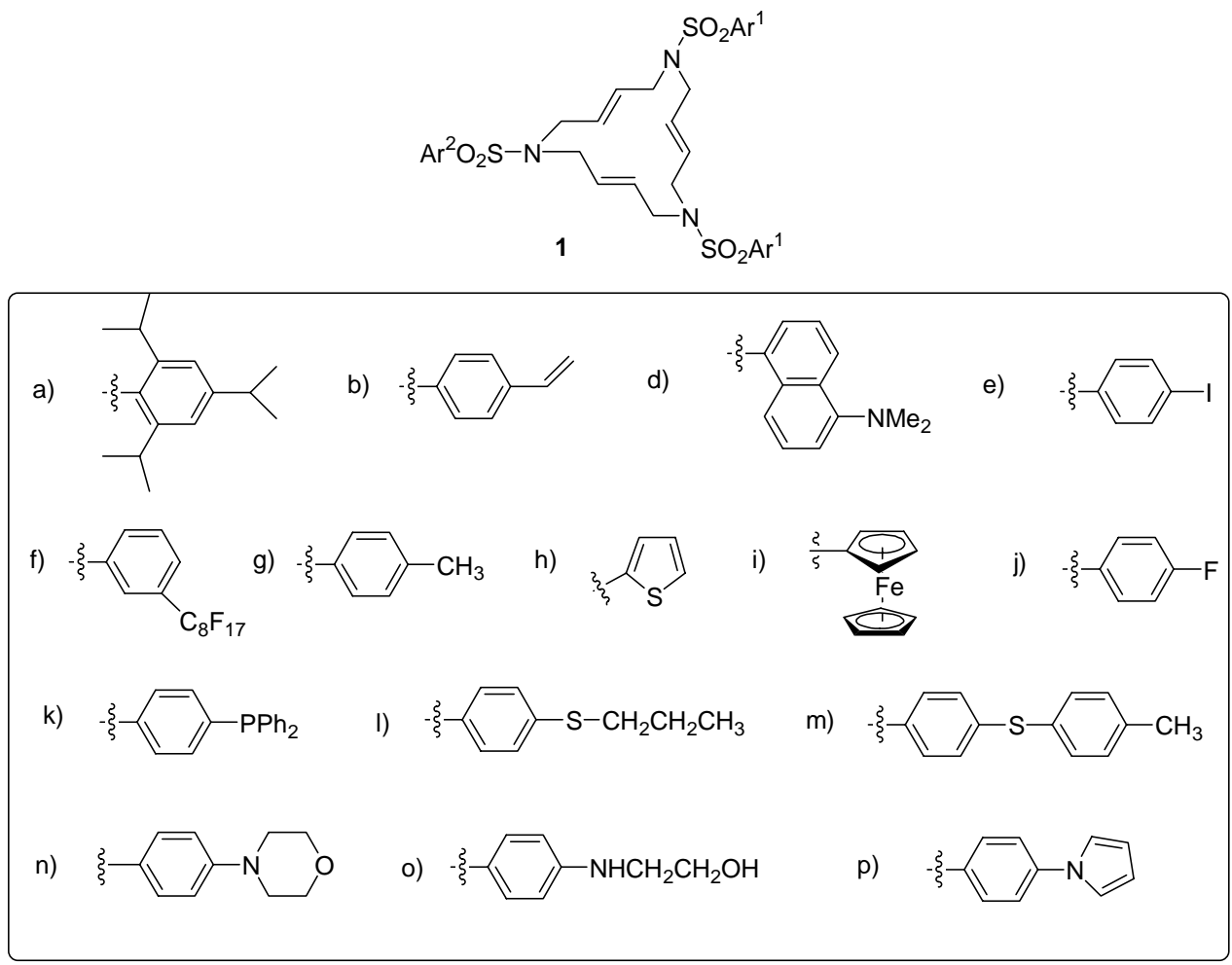

Figure 2. Substituents introduced in macrocycles 1.

Arenesulfonamides were chosen, so as to confer, enhance or modulate certain properties of the macrocycles. The presence of three isopropyl groups in the benzenesulfonyl moiety improves 
solubility of macrocycles in classical organic solvents (1aaa, 1aab, and 1aad). ${ }^{4,6-8}$ Instead, methyl groups impart crystallinity and permitted a X-ray study of 1ggg. ${ }^{7}$ Perfluorinated long chains were envisaged to improve the solubility of 1aff in perfluorinated solvents. ${ }^{7}$ Complexes containing ferrocenyl (1ggi, 1gii, 1iii, 1iip, and 1ipp), thienyl (1ggh, 1ghh) and 4-(pyrrol-1yl)phenyl (1iip, 1ipp, and 1ggp) units have interest for electrochemical purposes. ${ }^{9,11,12}$ From the point of view of applications of solid supports in catalysis, 1aab has been used to prepare polymer 1aac by copolymerization with styrene and divinylbenzene (vide infra). ${ }^{6}$ We have also prepared macrocycle $\mathbf{1} \mathbf{j} \mathbf{j j}$, featuring three fluorine atoms, that is a key intermediate for the synthesis of more elaborated macrocycles through aromatic nucleophilic substitution of the three fluorine atoms with phosphorus (1kkk), nitrogen (1nnn, 1000), and sulphur (1lll, 1mmm) nucleophiles. $^{10}$

Table 1. Summary of all-trans 15-membered macrocycles 1 synthesized

\begin{tabular}{|c|c|c|c|c|}
\hline Entry & Macrocycle & $\mathrm{Ar}^{1}$ & $\mathrm{Ar}^{2}$ & References \\
\hline 1 & 1aaa & $2,4,6-\mathrm{PrC}_{6} \mathrm{H}_{2-}$ & $2,4,6-i \mathrm{PrC}_{6} \mathrm{H}_{2-}$ & $4,6,7,8$ \\
\hline 2 & 1aab & $2,4,6-\mathrm{PPC}_{6} \mathrm{H}_{2-}$ & $4-\mathrm{CH}_{2}=\mathrm{CHC}_{6} \mathrm{H}_{4}-$ & 6,7 \\
\hline 3 & 1aac & $2,4,6-i \operatorname{PrC}_{6} \mathrm{H}_{2-}$ & 4-Polymer- ${ }^{\mathrm{a}}$ & 6 \\
\hline 4 & 1aad & $2,4,6-i \mathrm{PrC}_{6} \mathrm{H}_{2-}$ & 5-Dimethylaminonaphthyl- & 7 \\
\hline 5 & 1aee & $4-\mathrm{IC}_{6} \mathrm{H}_{4-}$ & $2,4,6-\mathrm{PrC}_{6} \mathrm{H}_{2-}$ & 7 \\
\hline 6 & 1aff & $3-\mathrm{C}_{8} \mathrm{~F}_{17} \mathrm{C}_{6} \mathrm{H}_{4-}$ & $2,4,6-i \mathrm{PrC}_{6} \mathrm{H}_{2-}$ & 7 \\
\hline 7 & 1ddd & 5-Dimethylaminonaphthyl- & 5-Dimethylaminonaphthyl- & 7 \\
\hline 8 & 1ggg & $4-\mathrm{CH}_{3} \mathrm{C}_{6} \mathrm{H}_{4}-$ & $4-\mathrm{CH}_{3} \mathrm{C}_{6} \mathrm{H}_{4}-$ & 7 \\
\hline 9 & 1ggh & $4-\mathrm{CH}_{3} \mathrm{C}_{6} \mathrm{H}_{4-}^{-}$ & 2-Thienyl- & 7 \\
\hline 10 & 1ghh & 2-Thienyl- & $4-\mathrm{CH}_{3} \mathrm{C}_{6} \mathrm{H}_{4}-$ & 7 \\
\hline 11 & 1ggi & $4-\mathrm{CH}_{3} \mathrm{C}_{6} \mathrm{H}_{4}-$ & Ferrocenyl- & 9,11 \\
\hline 12 & 1gii & Ferrocenyl- & $4-\mathrm{CH}_{3} \mathrm{C}_{6} \mathrm{H}_{4}^{-}$ & 9 \\
\hline 13 & 1iii & Ferrocenyl- & Ferrocenyl- & 9 \\
\hline 14 & $1 \mathbf{j j j}$ & $4-\mathrm{FC}_{6} \mathrm{H}_{4-}$ & $4-\mathrm{FC}_{6} \mathrm{H}_{4-}$ & 10 \\
\hline 15 & 1kkk & $4-\mathrm{Ph}_{2} \mathrm{PC}_{6} \mathrm{H}_{4}-$ & $4-\mathrm{Ph}_{2} \mathrm{PC}_{6} \mathrm{H}_{4}-$ & 10 \\
\hline 16 & 1111 & $4-\mathrm{CH}_{3} \mathrm{CH}_{2} \mathrm{CH}_{2} \mathrm{SC}_{6} \mathrm{H}_{4}-$ & $4-\mathrm{CH}_{3} \mathrm{CH}_{2} \mathrm{CH}_{2} \mathrm{SC}_{6} \mathrm{H}_{4}-$ & 10 \\
\hline 17 & $1 \mathrm{mmm}$ & $4-\mathrm{CH}_{3} \mathrm{C}_{6} \mathrm{H}_{4}-\mathrm{S}-\mathrm{C}_{6} \mathrm{H}_{4}^{-}$ & $4-\mathrm{CH}_{3} \mathrm{C}_{6} \mathrm{H}_{4}-\mathrm{S}-\mathrm{C}_{6} \mathrm{H}_{4}-$ & 10 \\
\hline 18 & 1nnn & 4-(Morpholino)phenyl- & 4-(Morpholino)phenyl- & 10 \\
\hline 19 & 1000 & 4- $\left(\mathrm{HOCH}_{2} \mathrm{CH}_{2} \mathrm{NH}\right) \mathrm{C}_{6} \mathrm{H}_{4^{-}}$ & $4-\left(\mathrm{HOCH}_{2} \mathrm{CH}_{2} \mathrm{NH}\right) \mathrm{C}_{6} \mathrm{H}_{4^{-}}$ & 10 \\
\hline 20 & 1iip & Ferrocenyl- & 4-(Pyrrol-1-yl)phenyl- & 12 \\
\hline 21 & 1ipp & 4-(Pyrrol-1-yl)phenyl- & Ferrocenyl- & 12 \\
\hline 22 & 1ggp & 4- $\mathrm{CH}_{3} \mathrm{C}_{6} \mathrm{H}_{4}^{-}$ & 4-(Pyrrol-1-yl)phenyl- & 12 \\
\hline
\end{tabular}

${ }^{\text {a }}$ Polymer of 1aab with styrene and divinylbenzene. 
We have reported three different synthetic pathways "a", "b", and "c" for the synthesis of the triazatriolefinic macrocycles $\mathbf{1}$ based on three different disconnecting approaches for the final condensation step (Figure 3$)^{7}$

In our initial synthesis corresponding to pathway "a" (Scheme 2), reaction of arenesulfonamides with trans-1,4-dibromo-2-butene gave a mixture of monosulfonamides 7 and bis-sulfonamides $\mathbf{6}$. Condensation of $\mathbf{6}$ with different arenesulfonamides was straightforward and led to the formation of macrocycles 1aaa, 1aab, 1aad, 1aee, 1ddd, 1ggh, 1jjj. The main problem of this synthesis is that bis-sulfonamides $\mathbf{6}$ are obtained as minor products. Optimization of this step has not been possible. However, compounds 6 can be obtained by reaction of bisarenesulfonamides 8 with excess trans-1,4-dibromobutene (Scheme 2). ${ }^{7}$
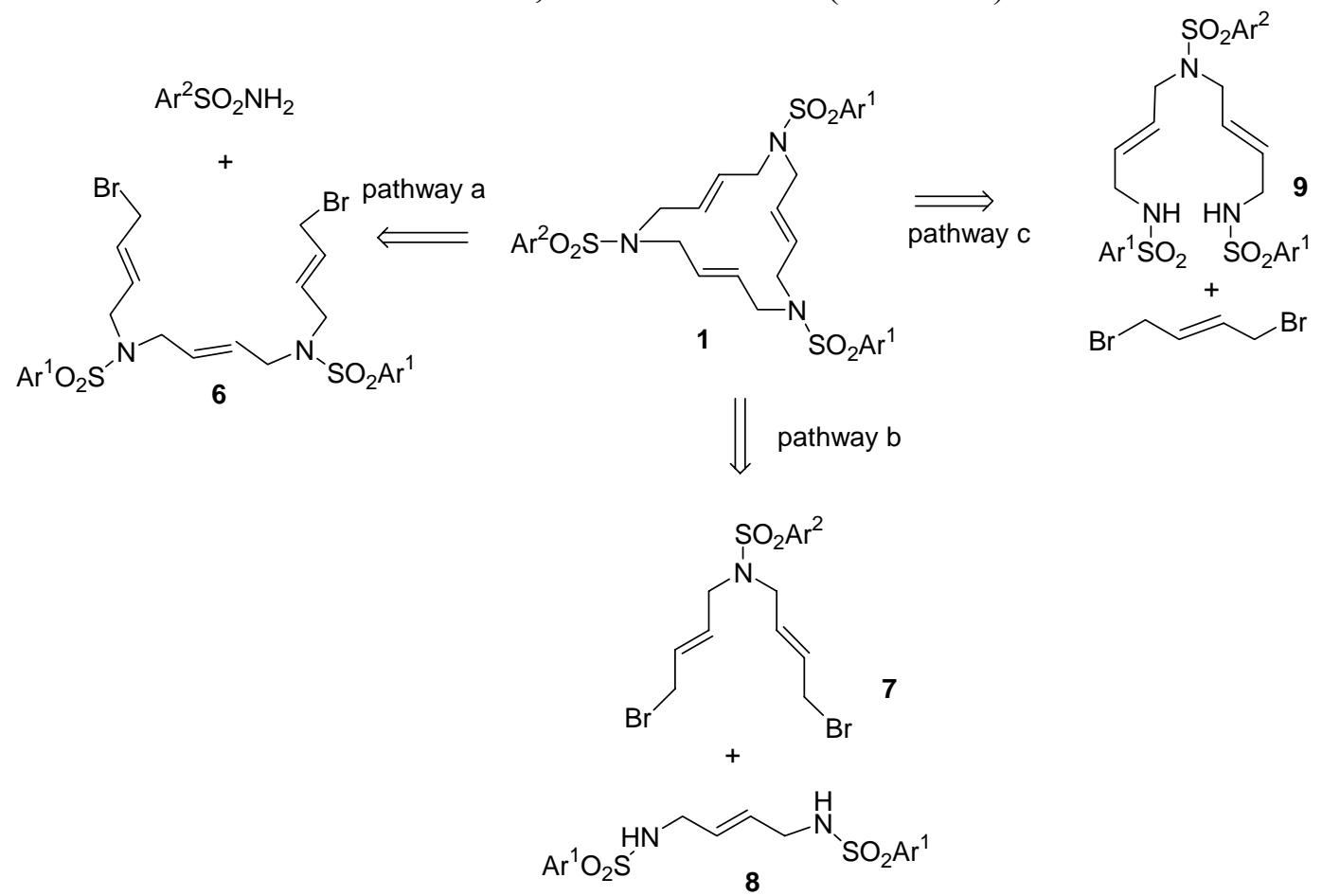

Figure 3. Retrosynthetic pathway for macrocycles 1.

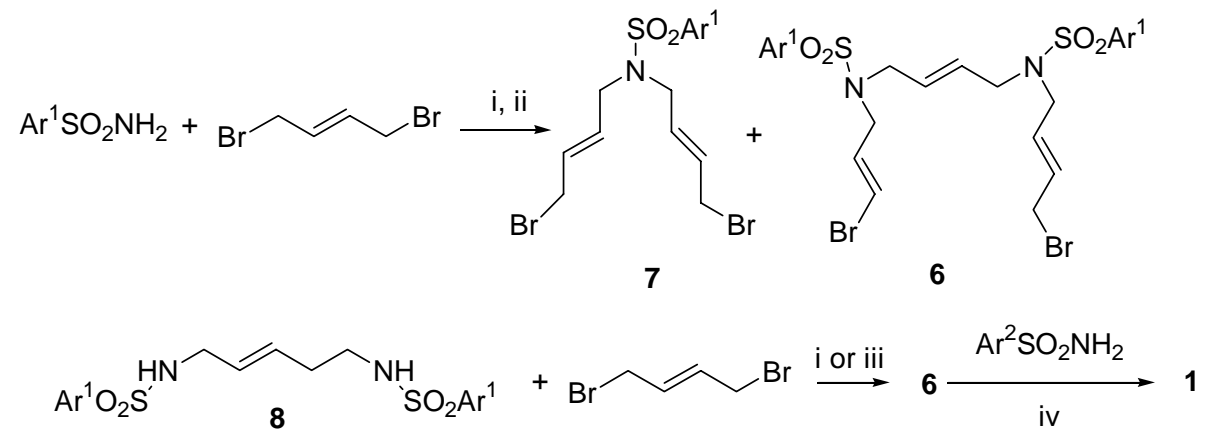

Scheme 2. Preparation according to pathway "a". Reagents and conditions: i.- NaH, DMF, then $\mathrm{BrCH}_{2} \mathrm{CH}=\mathrm{CHCH}_{2} \mathrm{Br}, 90^{\circ} \mathrm{C}$; ii.- column chromatography on silica gel; iii.- $\mathrm{K}_{2} \mathrm{CO} 3$, refluxing 
acetonitrile, then $\mathrm{BrCH}_{2} \mathrm{CH}=\mathrm{CHCH}_{2} \mathrm{Br}$ (8 equiv); iv.- $\mathrm{NaH}$, DMF over arenesulfonamide, then 6 , $90^{\circ} \mathrm{C}$.

Since in the first step of pathway "a" monosulfonamides 7 were obtained as major products, we soon envisaged another approach (Scheme 3). The preparation of macrocycles 1aaa, 1ghh and $\mathbf{1} \mathbf{j j j}$ was achieved by reaction of the more abundant $\mathbf{7}$ with $\mathbf{8} .{ }^{7,10}$ Compound 8 was prepared by two different ways. One way is based in the diarenesulfonylation of 2-butene-1,4-diamine, which was prepared by a Gabriel reaction using trans-1,4-dibromo-2-butene. ${ }^{6}$ Another way consists of a nucleophilic substitution reaction between two equivalents of $\mathbf{1 0}$ and trans-1,4dibromo-2-butene to obtain $11{ }^{6}$ Deprotection of $\mathbf{1 1}$ gave quantitative yields of $\mathbf{8}$.
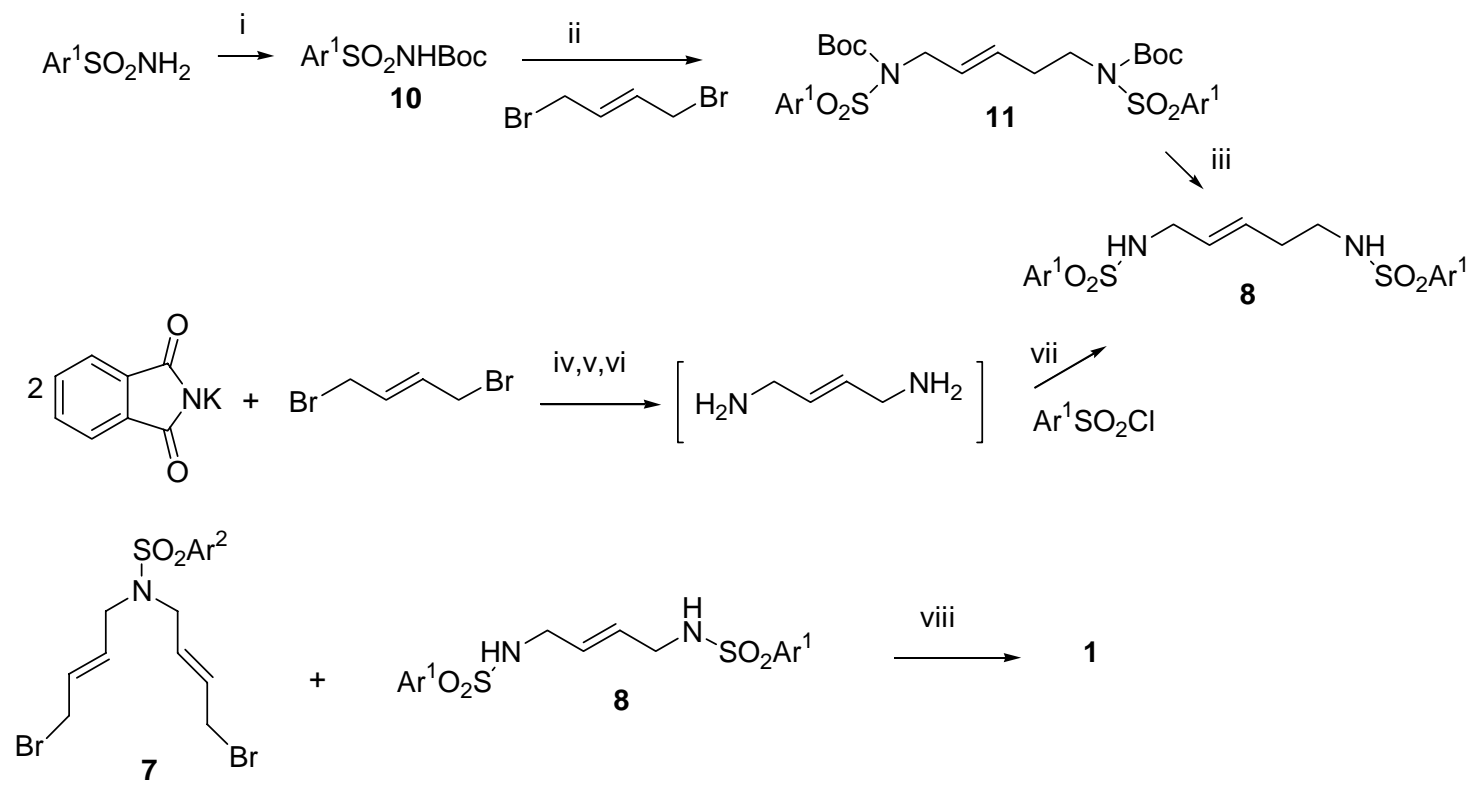

Scheme 3. Preparation according to pathway " $b "$. Reagents and conditions: i.- (tert-BuOCO) ${ }_{2} \mathrm{O}$, $\mathrm{Et}_{3} \mathrm{~N}$, DMAP (0.1 equiv), dichloromethane; ii.- $\mathrm{K}_{2} \mathrm{CO}_{3}$, acetonitrile, reflux or $\mathrm{K}_{2} \mathrm{CO}_{3}, \mathrm{DMF}$, room temperature, then trans-1,4-dibromo-2-butene ( 0.5 equiv); iii.- TFAA, dichloromethane, room temperature; iv.- DMF, $80{ }^{\circ} \mathrm{C}$; v.- $80 \%$ hydrazine, ethanol, reflux; vi.- $\mathrm{KOH}$, $\mathrm{H} 2 \mathrm{O}$; vii.diethyl ether; viii.- $\mathrm{NaH}$, DMF over 8 , then $7,90^{\circ} \mathrm{C}$.

Alternatively, macrocycles 1aff, 1ggg, 1ggi, 1gii, 1iii, 1iip, 1ipp, and 1ggp have been obtained in excellent yields by synthetic pathway "c" (Scheme 4). For the preparation of 9 the $\mathrm{NH}_{2}$ groups must be protected in $\mathbf{1 0}$ and $\mathbf{1 2}$ to avoid $\mathrm{N}$-dialkylation in step ii, and to obtain a successful reaction between 12 and the arenesulfonamide (step iii). 


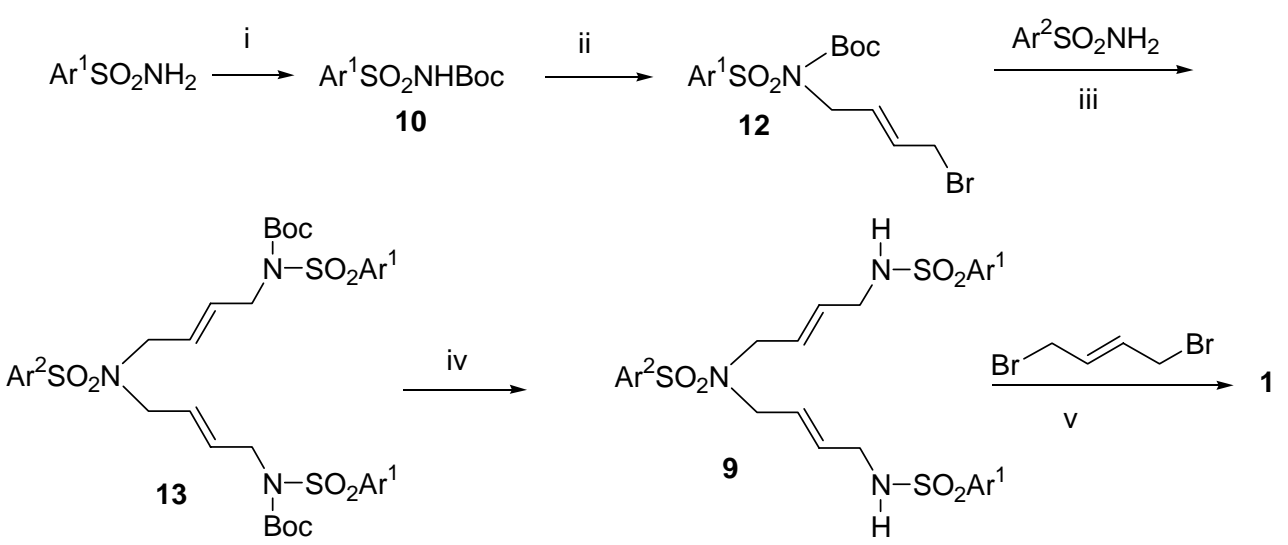

Scheme 4. Preparation according to pathway "c". Reagents and conditions: i.- (tert-BuOCO) ${ }_{2} \mathrm{O}$, $\mathrm{Et}_{3} \mathrm{~N}$, DMAP (0.1 equiv), dichloromethane; ii.- $\mathrm{K}_{2} \mathrm{CO}_{3}$, acetonitrile, trans-1,4-dibromo-2-butene (4 equiv), reflux; iii.- $\mathrm{K}_{2} \mathrm{CO}_{3}$, acetonitrile, arenesulfonamide (0.5 equiv), reflux; iv.- TFAA, dichloromethane, room temperature; v.- $\mathrm{K}_{2} \mathrm{CO}_{3}$, refluxing acetonitrile, trans-1,4-dibromo-2butene (4 equiv).

All three pathways "a", "b", and "c" are good enough. However, pathway "c" seems to be most convenient because of its versatility and it is the recommended one.

Moreover, further possibilities are offered by macrocycle $\mathbf{1} \mathbf{j j j} \mathbf{j}$, containing three fluorine atoms susceptible of substitution by nucleophiles. This pivotal compound has permitted us to increase the vast array of substituents possible (Scheme 5).

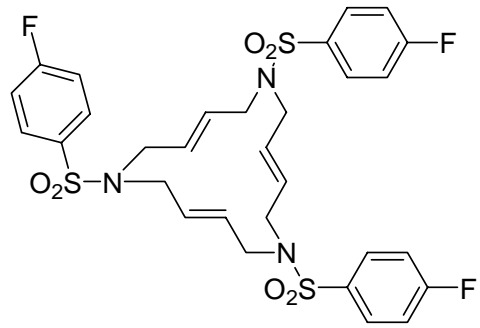

$1 j j j$

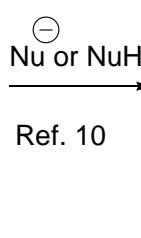

Ref. 10

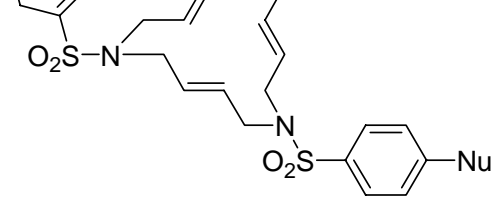

1kkk, 1 III, 1mmm, 1nnn, 1000

Scheme 5. Nucleophilic aromatic substitution on $\mathbf{1 j j j}$.

\subsection{Preparation of metal complexes}

The coordination ability of all-trans triazatriolefinic macrocycles with transition metals through the three double bonds, has been also studied. Thus, we have prepared a large amount of different transition metal macrocyclic complexes (Table 2). The palladium complexes 4 are obtained either by ligand-exchange using $\mathrm{Pd}\left(\mathrm{PPh}_{3}\right)_{4}$ or $\mathrm{Pd}(\mathrm{dba})_{2}$ as sources of metal ${ }^{4,6,8,11-15}$ or by in situ reduction of $\mathrm{PdCl}_{2}$ with hydrazine in the presence of the macrocycle. ${ }^{10}$ Excellent results 
are obtained with $\mathrm{Pt}\left(\mathrm{PPh}_{3}\right)_{4}$ to prepare platinum complexes 14, and less stable silver complexes 15 have been prepared from $\mathrm{AgBF}_{4}$.

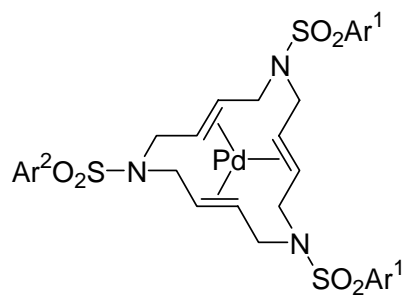

4

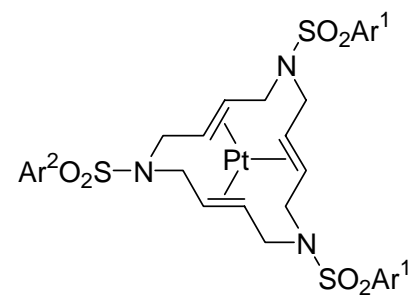

14



15

Figure 4. Palladium(0), platinum(0), and silver(I) complexes.

Table 2. Summary of transition metal complexes 4, 14 and 15 of all-trans 15-membered macrocycles 1

\begin{tabular}{|c|c|c|c|}
\hline Entry & Transition Metal Complexes & Applications in catalysis & References \\
\hline 1 & 4aaa & $\begin{array}{l}\text { Cross-coupling type reactions, } \\
\text { Butadiene telomerization }\end{array}$ & $4,6,8,14$ \\
\hline 2 & 4aac & Heterogeneous catalyst as above & 6 \\
\hline 3 & 4aff & & 13 \\
\hline 4 & 4ddd & & 13 \\
\hline 5 & 4ggg & Alkyne hydroarylation & 13,15 \\
\hline 6 & 4ggi & $\begin{array}{l}\text { Cross-coupling reaction, } \\
\text { Heck reaction }\end{array}$ & 9,11 \\
\hline 7 & 4gii & & 9 \\
\hline 8 & 4iii & & 9 \\
\hline 9 & 4kkk & & 10 \\
\hline 10 & 4iip & Cross-coupling type reactions & 12 \\
\hline 11 & 4ipp & Cross-coupling type reactions & 12 \\
\hline 12 & 4ggp & & 12 \\
\hline 13 & 14aaa & & 13 \\
\hline 14 & 14ggg & & 13 \\
\hline 15 & 15aаa & & 13 \\
\hline 16 & 15ggg & & 13 \\
\hline
\end{tabular}




\section{Structure and spectroscopy}

The structure of palladium complexes $\mathbf{4}$ has intrigued us since the moment of their discovery. As an example, significant ${ }^{13} \mathrm{C}$ and ${ }^{1} \mathrm{H}$ NMR data for compound 4aaa, as well as for their uncomplexed macrocyclic ligand 1aaa are summarized in Figure 5. The free ligand 1aaa presented in its ${ }^{1} \mathrm{H}$ NMR spectrum only one signal at $\delta 3.77$ for the twelve methylene protons, and in its ${ }^{13} \mathrm{C}$ NMR spectrum only one signal at $\delta 49.2$ for the six methylene carbons; for the olefinic part, the ${ }^{1} \mathrm{H}$ NMR spectrum showed one olefinic signal at $\delta 5.79$ for the six olefinic protons and the ${ }^{13} \mathrm{C}$ NMR spectrum presented only one signal at $\delta 123.9$. All these data suggest that compound 1aaa has an averaged $C_{3}$ axis of symmetry. In contrast, complex 4aaa presented two magnetically equivalent olefinic systems with magnetically non-equivalent protons at $\delta 2.80$ $\left(\mathrm{H}_{\mathrm{a}}\right.$, apparent $\left.\mathrm{t}, J=12.4 \mathrm{~Hz}, 2 \mathrm{H}\right)$ and $\delta 4.10\left(\mathrm{H}_{\mathrm{b}}, \mathrm{dd}, J=12.4 \mathrm{~Hz}\right.$ and $\left.11.1 \mathrm{~Hz}, 2 \mathrm{H}\right)$ plus a different olefinic system with magnetically equivalent protons at $\delta 3.85\left(\mathrm{H}_{\mathrm{c}}\right.$, apparent $\mathrm{d}, J=9.5$ $\mathrm{Hz}, 2 \mathrm{H})$. The strong upfield shift of olefinic signals as well as the trans coupling constant value of $c a .12 \mathrm{~Hz}$ are normal for olefin- $\mathrm{Pd}(0)$ complexes such as the palladium bis(dibenzylidene)acetone. ${ }^{16}$ 2D NOESY experiments confirmed the trans-stereochemistry of the olefins. Clearly the third olefinic system in the ring is also coordinated to palladium but in a different way. ${ }^{13} \mathrm{C}$ NMR spectrum showed also three different olefinic carbon atoms $(79.2,79.3$ and 83.7) shifted by $\Delta \delta_{\mathrm{c}}=40-44 \mathrm{ppm}$ upfield as compared to the free ligand 1aaa. These facts suggest that the presence of the palladium atom breaks the symmetry of the compound and the complexation of palladium by one olefin is different with respect to the other two.

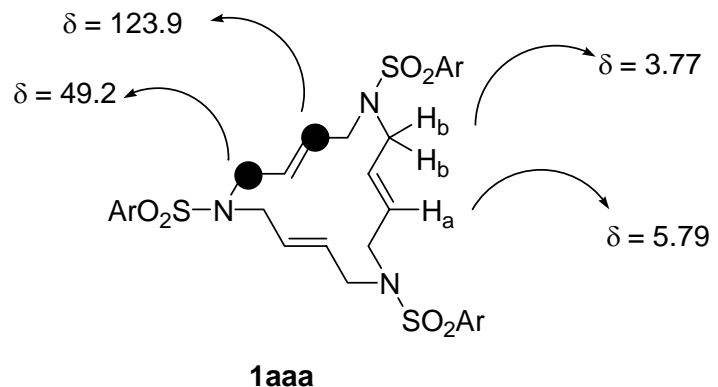

1 aaa

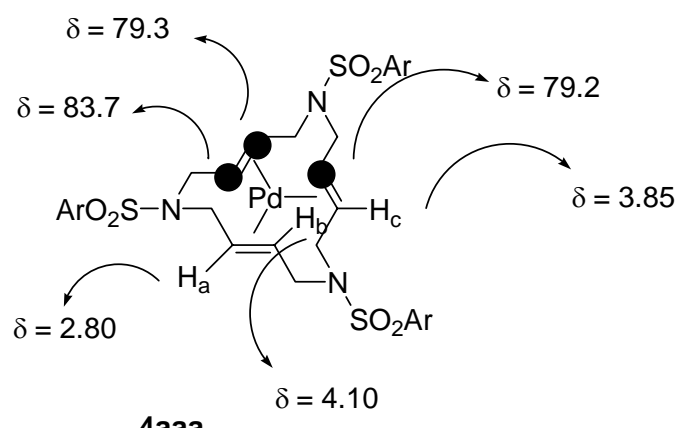

4aaa

$$
\mathrm{Ar}=2,4,6-\mathrm{PrC}_{6} \mathrm{H}_{2-}
$$

Figure 5. Significant ${ }^{1} \mathrm{H}$ and ${ }^{13} \mathrm{C}$ NMR signals for compound 1aaa and their palladium(0) complex 4aaa.

The same behavior is evident for other macrocycles containing three identical aryl groups on the basis of similar NMR spectra, and also for the corresponding platinum(0) complexes, 14. Since the silver complexes 15 were not stable, they could not be studied in depth. Selected NMR data for complexes $\mathbf{4}$ and $\mathbf{1 4}$ are tabulated in Table 3 . 
Table 3. Selected NMR data ${ }^{a}$ for complexes $\mathbf{4}$ and $\mathbf{1 4}$ bearing three identical aryl units

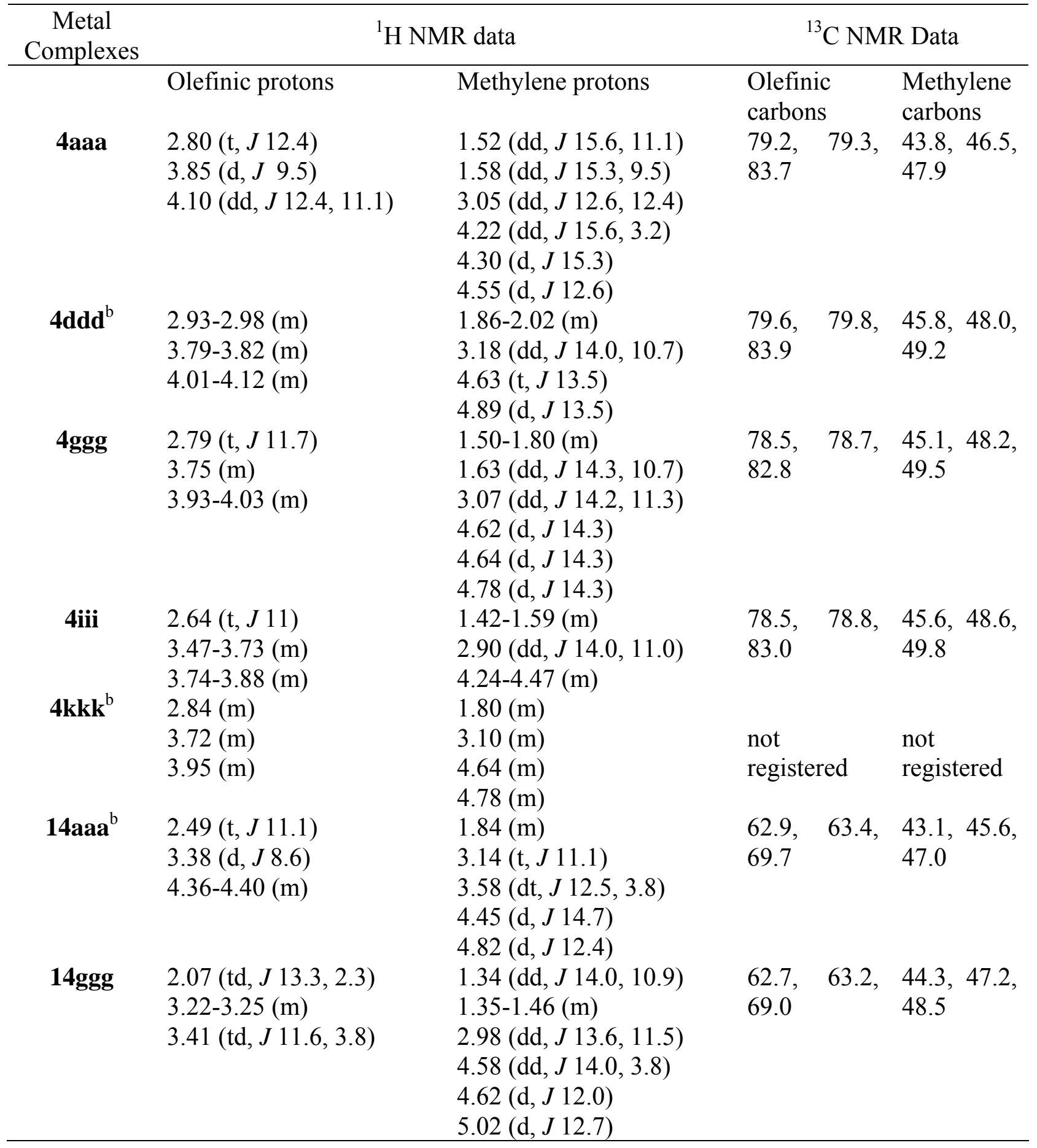

${ }^{a}$ Chemical shifts and coupling constants were determined by selective 1D TOCSY experiments.

${ }^{b}$ Assignment of chemical shifts for olefinic and methylenic protons has been done by similarity with compounds 4aaa, 4ggg, 4iii, and 14ggg that have undergone a full NMR analysis. 
Strong evidence in support of these facts was secured by X-ray diffraction for 4ggg and 14ggg. In 4ggg the middle point of the olefinic bonds and the metal center are all situated in the same plane and thus the coordination of the metal center is planar trigonal. The complex is not symmetrical, and, as it has been seen by NMR data, it lacks a $\mathrm{C}_{3}$ symmetry axis. Two $\mathrm{C}=\mathrm{C}$ bonds are longer than in the corresponding free ligand 1aaa. However, the third $\mathrm{C}=\mathrm{C}$ bond is shorter that the other two in the complex, suggesting that complexation with one olefin is weaker than complexation by the other two.

In complexes 4 possessing two different aryl units $\left(\mathrm{Ar}^{1} \neq \mathrm{Ar}^{2}\right)$ two isomers exist depending on which substituent occupies the position opposite to the singular olefin. The ${ }^{13} \mathrm{C}$ NMR spectra confirm the existence of isomers in solution: three carbon signals are found for a symmetrical isomers, but six more signals were found for isomer lacking symmetry elements. Selected ${ }^{13} \mathrm{C}$ NMR data for complexes $\mathbf{4}$ bearing two different aryl units are shown in Table 4. Further structural studies based on complexes $\mathbf{4}$ with three different aryl units are in progress.

Table 4. Selected ${ }^{13} \mathrm{C}$ NMR spectroscopic data for complexes $\mathbf{4}$ bearing two different aryl units

\begin{tabular}{cll}
\hline Complexes & \multicolumn{1}{c}{ Olefinic carbon atoms } & \multicolumn{1}{c}{ Methylene carbon atoms } \\
\hline 4aff & $77.6,77.9,78.6,78.8,79.7,79.9,81.9,82.8,84.4$ & $34.1,43.7,45.2,45.4,46.3$, \\
& & $47.6,48.2,49.3,49.5$ \\
4ggi & $78.1,78.2,78.3,78.4,78.6,78.7,82.5,82.6,82.9$ & $45.1,48.1,48.2,49.3,49.4$ \\
4gii & $78.0,78.2,78.3,78.4,78.7,82.4,82.7,82.8$ & $45.1,48.1,48.2,49.4,49.5$ \\
4iip & $77.8,78.1,78.4,78.6,78.7,78.9,82.2,82.9,83.1$ & $45.1,45.2,48.1,48.2,49.3$, \\
& & $49.4,49.5$ \\
4ggp & $78.1,78.3,78.5,78.6,78.7,78.8,82.4,82.9,83.0$ & $45.0,45.2,48.2,49.4$ \\
\hline
\end{tabular}

We chose Matrix-Assisted Laser Desorption/Ionization, time-of-flight (MALDI-TOF) and Electrospray Ionization Mass Spectrometry (ESI-MS) as analytical mass spectrometric techniques to identify complexes of type 4, 14, and 15. Both techniques allow heavy molecules to be efficiently ionized and vaporized without degradation. Initially, MALDI-TOF mass spectrometry allowed the direct determination of the extent of macrocyclic and linear oligomer formation in the palladium(0)-catalyzed allylation of arenesulfonamides with 2-butene-1,4-diol biscarbonate $^{5}$ (Scheme 1). Later on, mass spectroscopic investigations were performed to elucidate the structure of all complexes. Compounds of type 4, 14, and 15 were easily identified by the characteristic isotope distribution of the metal. Isotopic abundance of clusters was compared with calculated values. Figure 6 displays a positive-ion electrospray mass spectrum of complex 14ggg showing one peak at $\mathrm{m} / \mathrm{z} 865$ corresponding to $[\mathrm{M}+\mathrm{H}]^{+}$. The inset shows the isotope distribution pattern for the $m / z 864$ ion corresponding to $[\mathrm{M}]^{+}$. 


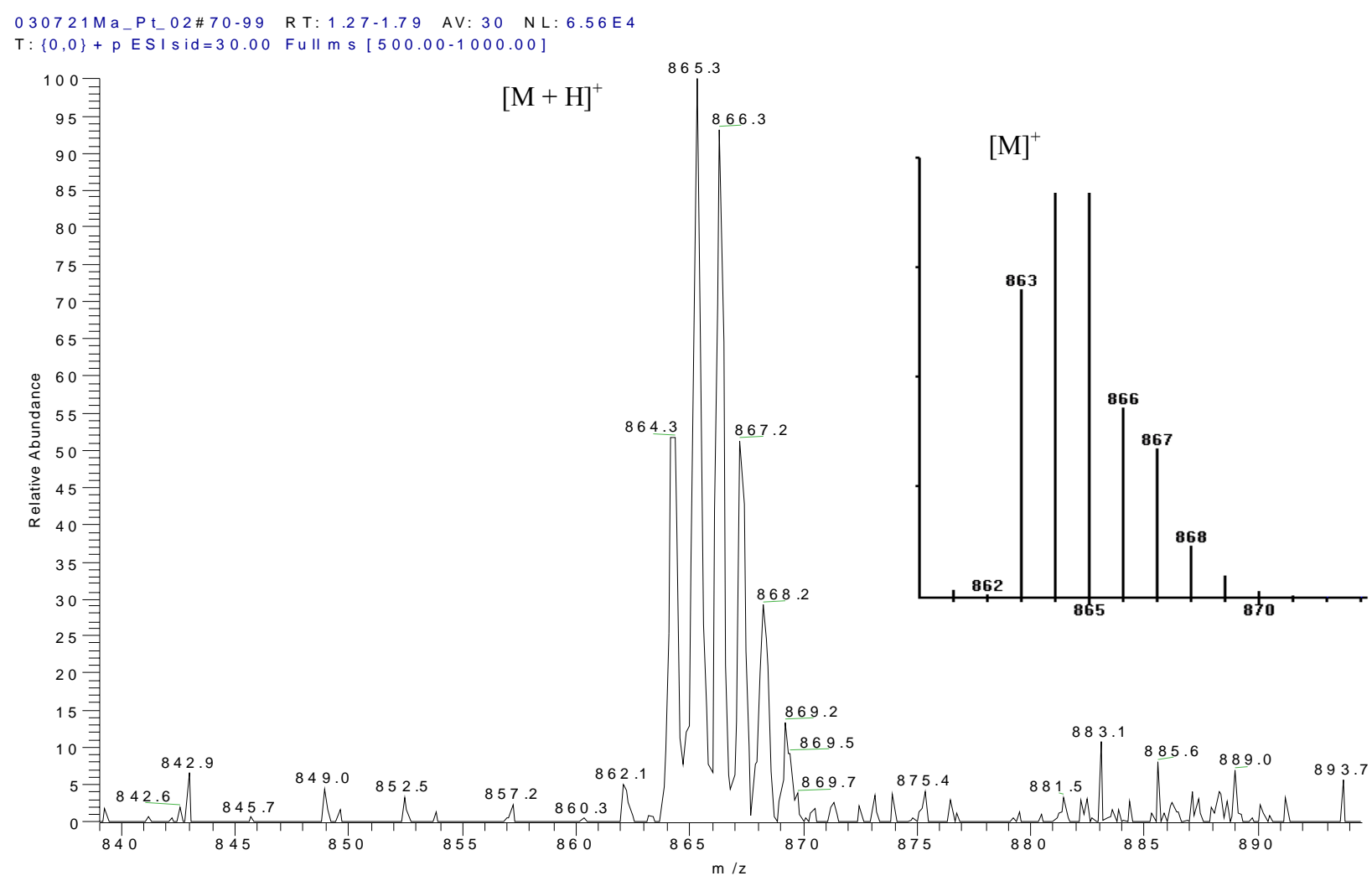

Figure 6. Positive-ion electrospray mass spectrum of complex 14ggg in $\mathrm{CH}_{3} \mathrm{CN} / \mathrm{H}_{2} \mathrm{O}(70 / 30)+0.05 \%$ TFA. The inset shows the calculated isotope pattern for the $[\mathrm{M}]^{+}$ion $(\mathrm{m} / \mathrm{z} 864)$.

\section{Catalysis}

Phosphine-free triolefinic palladium complexes 4, being air and moisture stable, were considered good candidates as recoverable $\operatorname{Pd}(0)$ catalysts. We first tested ${ }^{6}$ complex 4aaa as catalyst in the Suzuki-type cross-coupling. ${ }^{17}$ Thus, cinnamyl bromide, 16, reacts with arene boronic acids, 17ae, affording diarylpropenes 18a-e in good yields (Scheme 6). The reactions were performed with unoptimized $4-5 \%$ molar of catalyst in toluene at $80-90^{\circ}$ in the presence of potassium carbonate as base. In all cases the complex 4aaa was quantitatively recovered by column chromatography on silica gel. 


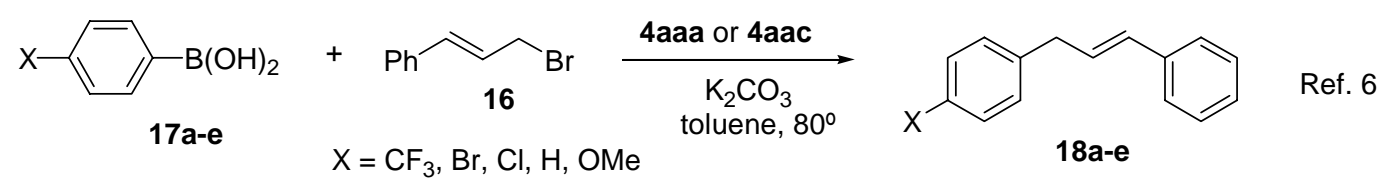

$75-99 \%$ yield with 4 aaa, recovery of 4 aaa by chromatography

5 runs for each $\mathrm{X}-\mathrm{Ph}-\mathrm{B}(\mathrm{OH})_{2}$ with 4 aac, similar yields, recovery of 4 aac by filtration

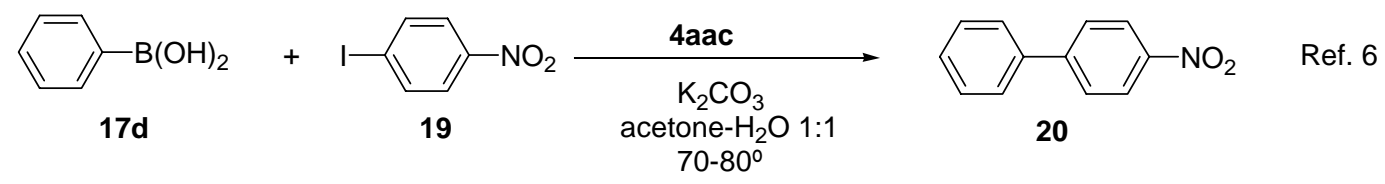

5 runs with the same batch of 4 aac: $82,91,94,96,89 \%$. Quantitative recovery of 4 aac by filtration

Scheme 6. Macrocyclic complexes 4 as catalysts in Suzuki-type couplings.

Anchoring the homogeneous catalyst to an insoluble organic polymer allows easy complex recovery by simple filtration. Thus, the macrocycle-containing cross-linked polystyrene catalyst 4aac was tested ${ }^{6}$ in the same reaction (Scheme 6). Five consecutive runs for each areneboronic acid were performed with the same batch of catalyst, which was quantitatively recovered by filtration and reused in the next run without decrease of activity. Polymer 4aac was also an efective catalyst $^{6}$ in the Suzuki cross-coupling between 4-iodonitrobenzene 19 and phenylboronic acid 17d to afford nitrobiphenyl 20 (scheme 6). The reaction was performed in acetone-water $(1: 1)$ at $70-80^{\circ}$ in the presence of potassium carbonate, with recovery and reuse as mentioned before.

The pyrrole groups of complexes containing ferrocenyl and pyrrole groups, 4iip and 4ipp, were electropolymerized upon exposure to sufficiently positive potentials, in order to generate highly stable modified electrodes. Ferrocenyl groups were attached for electrochemical monitoring of the polymerization process. These polypyrrole modified electrodes are efficient heterogeneous catalysts for the same cross-coupling reactions of Scheme $6 .^{12}$

Catalytic activity does not depend on the aryl substitution on the macrocycle. Thus, complex 4ggi is also a good catalyst ${ }^{9}$ for the Suzuki-type reaction between iodobenzene 21 and phenylboronic acid 17d $\left(\mathrm{K}_{2} \mathrm{CO}_{3}\right.$, acetone-water $\left.1: 1,60^{\circ}\right)$ and for the Heck reaction ${ }^{18}$ of ethyl acrylate 23 with iodobenzene 21 (KOAc, $\mathrm{Bu}_{4} \mathrm{NBr}, \mathrm{DMF}, 60^{\circ}$ ) (Scheme 7). In both cases complex 4ggi was recovered by column chromatography on silica gel in 95 and 55\% yield, respectively. For the Heck reaction the rest of the macrocyclic catalyst was recovered as uncomplexed 1ggi.

The above mentioned partial decomplexation in the Heck reaction led us to consider arenediazonium salts as substrates for that reaction, as they present some advantages, such as superior reactivity of the nucleofuge $\left(\mathrm{N}_{2}\right)$ over bromide and iodide, short reaction times, and mild reaction conditions without added base. Indeed, complex 4ggi efficiently catalyzed ${ }^{11}$ the arylation of acrylates and styrene with different arenediazonium tetrafluoroborates $\mathbf{2 7 a - g}$ in ethanol at room temperature (Scheme 7). Recovery of 4ggi by column chromatography was 
practically quantitative. ESI-MS studies ${ }^{19}$ provided evidence for oxidative addition species formed in the catalytic cycle immediately before the rate-limiting step. ${ }^{11}$

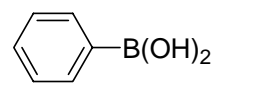

$17 d$

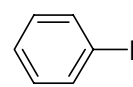

21

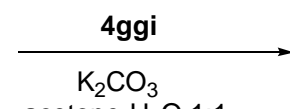

acetone- $\mathrm{H}_{2} \mathrm{O}$ 1:1

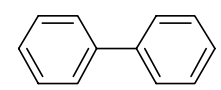

$22(70 \%)$

Ref. 9

$95 \%$ recovery of $\mathbf{4 g g i}$ by chromatography

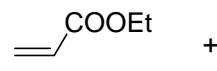

23

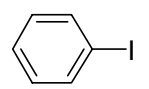

21

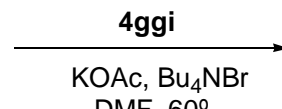

DMF, $60^{\circ}$

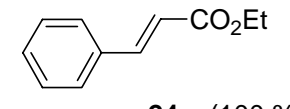

$24 a(100 \%)$
Ref. 9

$55 \%$ recovery of $\mathbf{4 g g i}$ by chromatography, the rest as uncomplexed $\mathbf{1 g g i}$

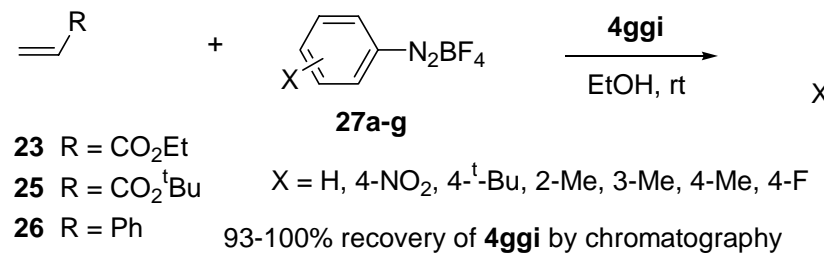

$$
\begin{aligned}
& \text { 24a-g R }=\mathrm{CO}_{2} \mathrm{Et} \quad(78-100 \%) \\
& \text { 28a-g R }=\mathrm{CO}_{2}{ }^{\mathrm{t}} \mathrm{Bu} \quad(71-100 \%) \\
& \text { 29a-d } \mathrm{R}=\mathrm{Ph} \quad(38-100 \%)
\end{aligned}
$$

Scheme 7. Macrocyclic complexes 4 as catalysts in Suzuki-type couplings and in Heck reactions.

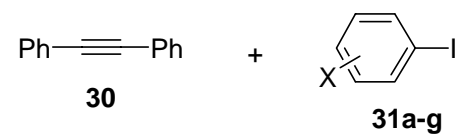

$\mathrm{X}=4-\mathrm{MeO}, 3-\mathrm{MeO}, 4-\mathrm{F}, 4-\mathrm{MeCO}_{4} 4-\mathrm{EtO}_{2} \mathrm{C}, 3-\mathrm{EtO}_{2} \mathrm{C}, 2-\mathrm{NO}_{2}-4-\mathrm{Me}$

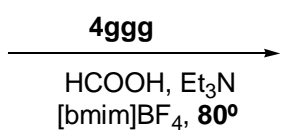

$[\mathrm{bmim}] \mathrm{BF}_{4}, \mathbf{8 0}^{\circ}$ without noticeable lose of activity

Scheme 8. Macrocyclic complexes 4 as catalyst in hydroarylation reactions in ionic solvents.

S. Cacchi's group has found ${ }^{15}$ that the hydroarylation of alkynes in ionic liquids can be efficiently conducted with our macrocyclic catalysts. Thus, diphenylacetylene $\mathbf{3 0}$ reacts with aryl iodides 31a-g and triethylamine/formic acid under catalyst by 4ggg, in 1-butyl-3methylimidazolium tetrafluoroborate $\left([\mathrm{bmim}] \mathrm{BF}_{4}\right)\left(\mathrm{Scheme}^{8}\right)$. The ionic solution containing the catalyst can be recycled and reused in six runs without loss of activity. Other classical palladium sources gave poorer results with respect to yields and recovery. The procedure has been applied ${ }^{15}$ to the preparation of 3-arylquinolines through a domino hydroarylation/cyclization process. 
Macrocyclic palladium complexes $\mathbf{4}$ were not catalytically active in telomerization and in Tsuji-Trost allylation reactions in the absence of added phosphine. ${ }^{8,14}$ However, J. Muzart, F. Henin and coworkers showed ${ }^{8,14}$ that the telomerization of butadiene with methanol can be performed with 4aaa and monodentate phosphines, the catalytic species being recycled up to four times by adding fresh phosphine each time (Scheme 9).

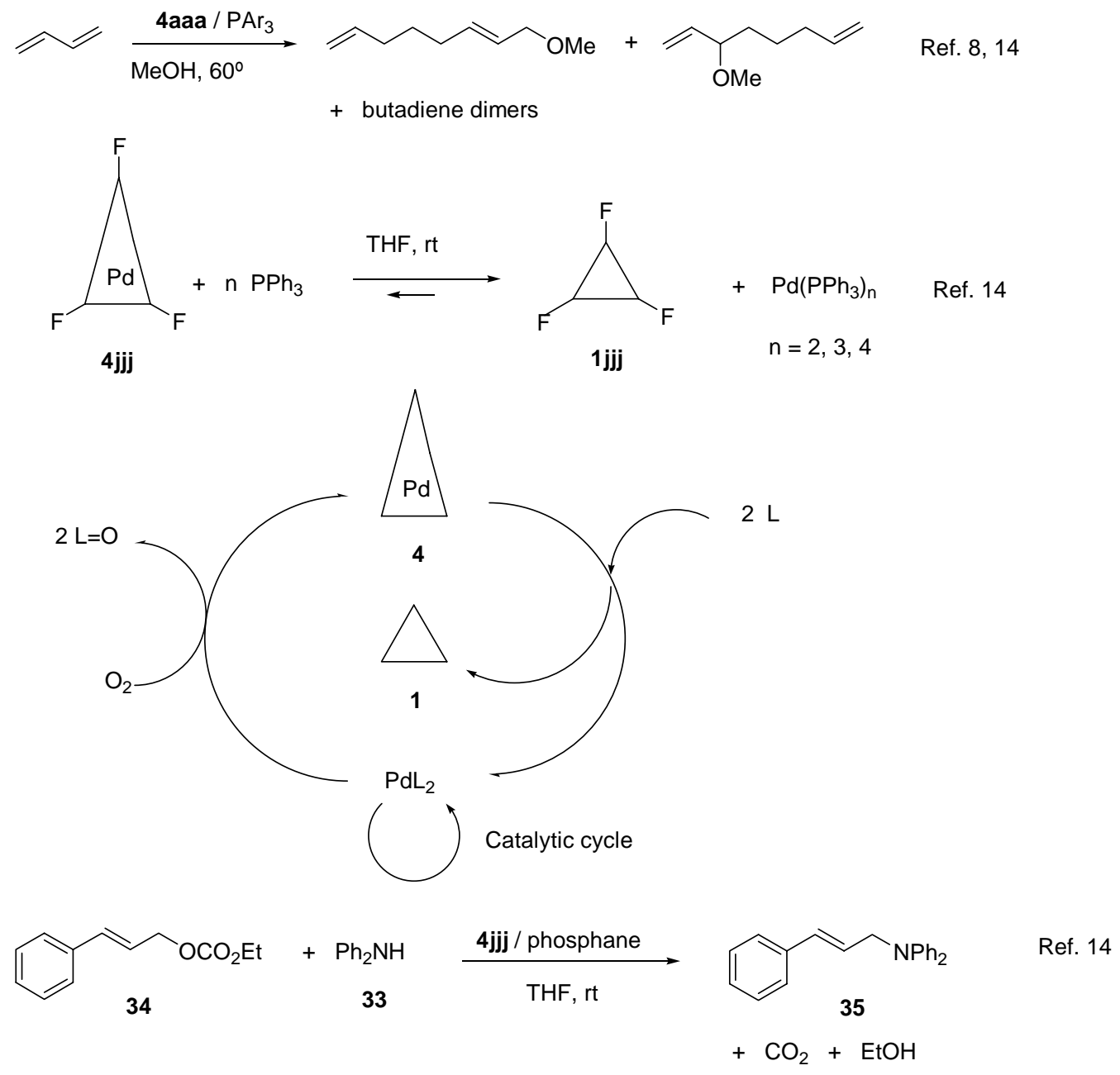

Scheme 9. Role of macrocyclic complexes 4 in telomerization and Tsuji-Trost reactions.

Moreover, the addition of free macrocycle 1aaa to the catalytic systems formed in situ from palladium sources $\left(\mathrm{Pd}(\mathrm{dba})_{2}, \mathrm{Pd}(\mathrm{OAc})_{2}\right)$ associated with phosphines has a stabilizing effect on palladium and allowed the recovery and reuse of the catalyst after addition of fresh phosphine each time. This was not possible without added 1aaa. To get information about the real catalytic species in the telomerization reaction in the presence of macrocycle, we undertook mechanistic

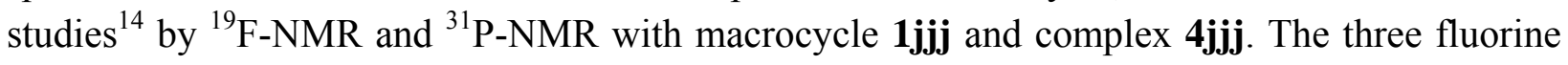
atoms show one signal in the ligand $\mathbf{1} \mathbf{j} \mathbf{j j}$, whereas the complex $\mathbf{4} \mathbf{j} \mathbf{j j}$ shows two fluorine signals of relative intensity 1:2. The conclusions are in Scheme 9. Complex 4jjj reacts with two moles of 
phosphine (or one mole of bidentate phosphine) to afford directly the highly active 14-electron $\mathrm{PdL}_{2}$ species. After catalysis ends up, if the phosphine is oxidized, palladium $(0)$ reverts to the free macrocycle $\mathbf{1} \mathbf{j} \mathbf{j j}$, to be stored as complex $\mathbf{4} \mathbf{j} \mathbf{j j}$, thus preventing agglomeration and remaining available for a new reaction, that requires addition of fresh phosphine but not of fresh palladium.

The allylation of diphenylamine 33 with cinnamyl carbonate 34 (Scheme 9) in the presence of $\mathbf{4 j j j}$ and phosphine in THF at room temperature to give 35 was also monitored ${ }^{14}$ by ${ }^{19} \mathrm{~F}$ and ${ }^{31} \mathrm{P}-\mathrm{NMR}$, the results being consistent with the same mechanistic proposal. Further evidence of the formation of intermediate species $\mathrm{PdL}_{\mathrm{n}}$ when macrocycles 4 react with phosphines was gained by an ESI-MS study ${ }^{14}$ of the reactions between complex 4ggi and several phosphines in THF.

\section{Related macrocycles}

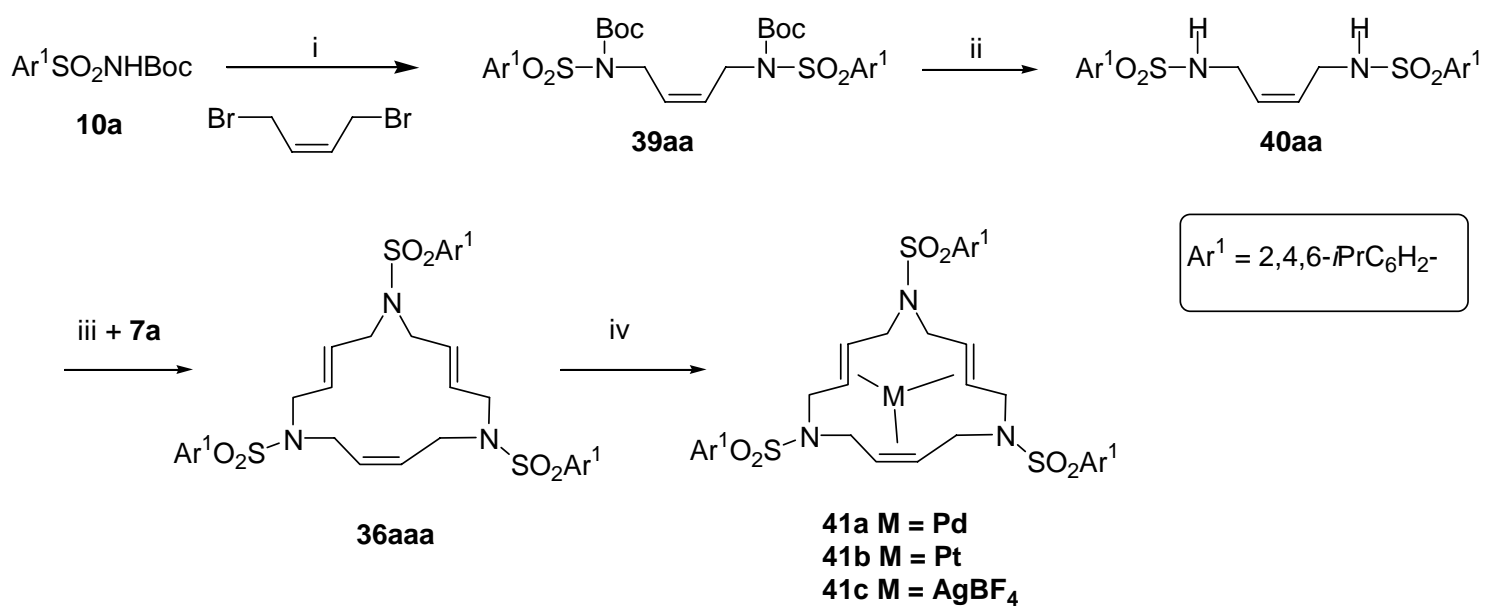

Scheme 10. Preparation of macrocycle 36. Reagents and conditions: i.- $\mathrm{K}_{2} \mathrm{CO}_{3}$, acetonitrile, reflux, then cis-1,4-dibromobutene (0.5 equiv); ii.- TFAA, dichloromethane, room temperature; iii.- $\mathrm{K}_{2} \mathrm{CO}_{3}$, refluxing acetonitrile; iv.- $\mathrm{Pd}\left(\mathrm{PPh}_{3}\right)_{4}$, refluxing THF, or $\mathrm{Pt}\left(\mathrm{PPh}_{3}\right)_{4}, \mathrm{DMF}, 130^{\circ} \mathrm{C}$, or $\mathrm{AgBF}_{4}$, refluxing acetone.

We have increased the family of our 15-membered macrocycles modifying the olefin precursors with the aim of studying the complexating ability of the new members of the family. Thus, we have prepared (E,E,Z)-1,6,11-tris[(2,4,6-triisopropylphenyl)sulfonyl]-1,6,11triazacyclopentadeca-3,8,13-triene, 36, (Scheme 10), ${ }^{20}$ (E,E)-1,6,11-tris(arenesulfonyl)-3,4benzo-1,6,11-triazacyclopentadeca-8,13-dienes, 37 (Scheme 11), ${ }^{21}$ and 1,6,11tris(arenesulfonyl)-3,4;8,9;13,14-tribenzo-1,6,11-triazacyclopentadecanes, 38 (Scheme 12). ${ }^{21}$

Macrocycle 36 featuring one cis double bond was synthesized through pathway "b" as indicated in Scheme 10. ${ }^{20}$ It forms palladium(0), platinum(0), and silver(I) complexes 41, the same as its all-trans counterpart 1aaa. However, preparation of $\mathbf{3 6}$ has the disadvantage that cis1,4-dibromo-2-butene has to be prepared whereas its trans isomer is commercially available. 


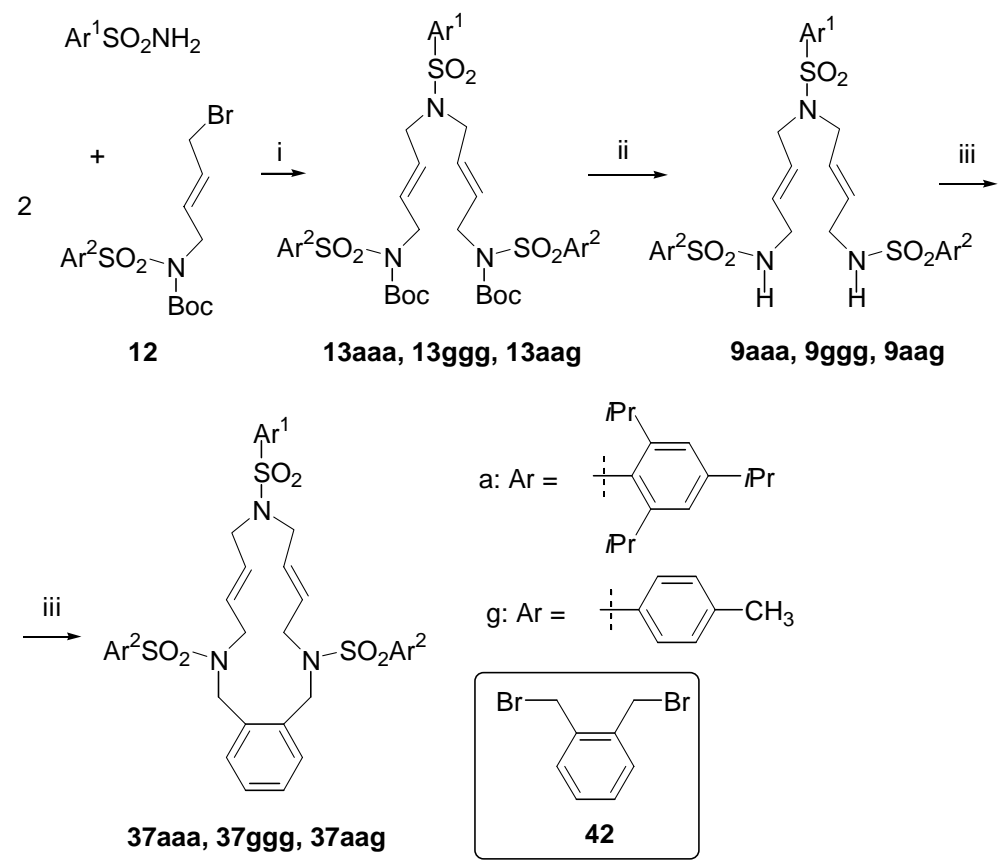

Scheme 11. Preparation of macrocycles 37. Reagents and conditions: i.- $\mathrm{K}_{2} \mathrm{CO}_{3}$, refluxing acetonitrile; ii.- TFAA, dichloromethane, room temperature; iii.- 42 (one equiv), $\mathrm{K}_{2} \mathrm{CO}_{3}$, refluxing acetonitrile.

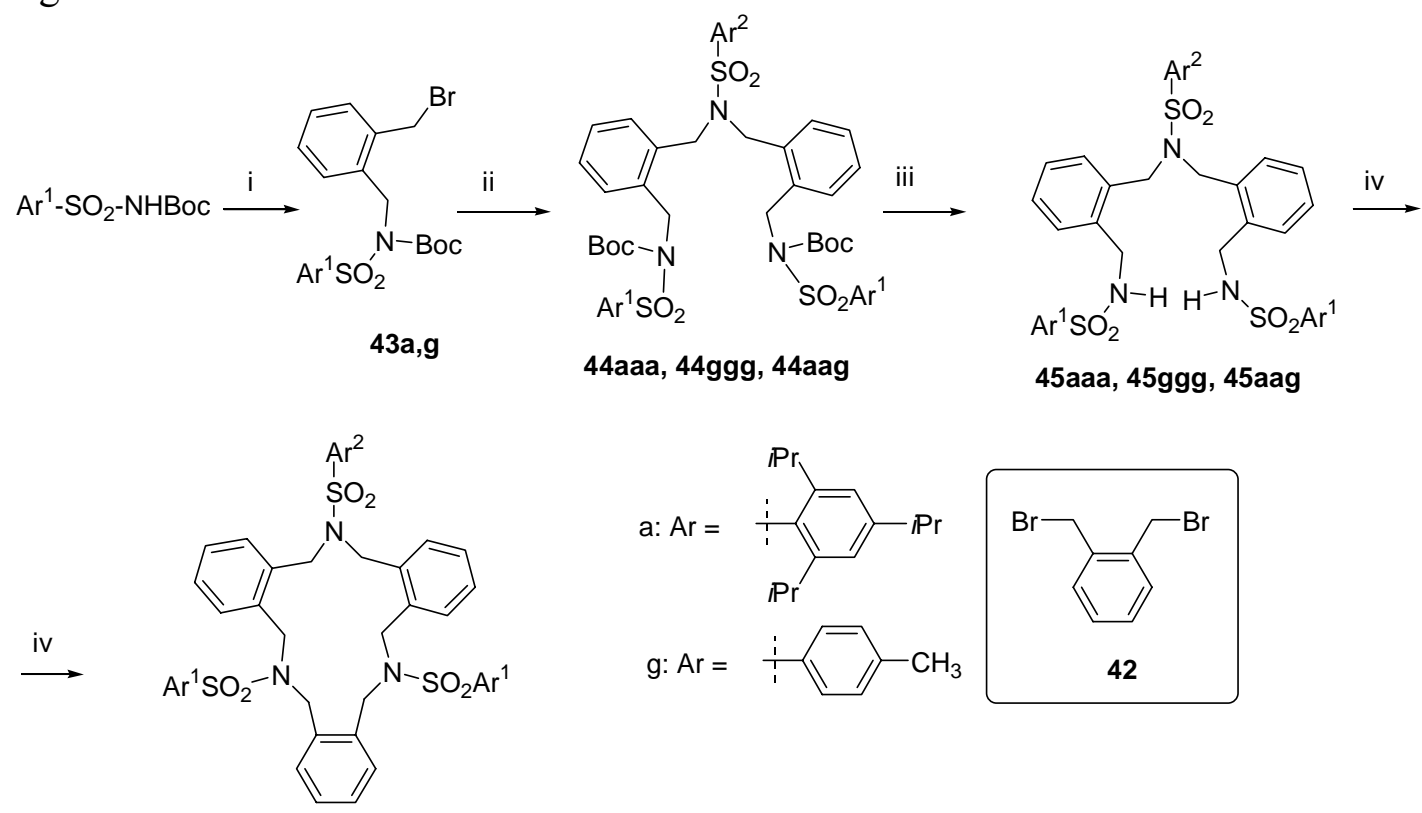

38aaa, 38ggg, 38aag

Scheme 12. Preparation of macrocyles 38. Reagents and conditions: i.- 42 (four equiv), $\mathrm{K}_{2} \mathrm{CO}_{3}$, refluxing acetonitrile; ii.- $\mathrm{Ar}^{2} \mathrm{SO}_{2} \mathrm{NH}_{2}$ (0.5 equiv), $\mathrm{K}_{2} \mathrm{CO}_{3}$, refluxing acetonitrile; iii.- TFAA, dichloromethane, room temperature; iv.- 42 (1 equiv), $\mathrm{K}_{2} \mathrm{CO}_{3}$, refluxing acetonitrile. 
Pathway "c" was followed for the synthesis of macrocycles 37 and $38 .^{21}$ In these cases trans1,4-dibromo-2-butene was substituted by 1,2-bis(bromomethyl)benzene in the required steps (Schemes 11 and 12). This type of synthesis is versatile, and it permits once more one to combine different aryl groups at different synthetic steps. Moreover, the cyclization step is excellent, the formation of higher cycles and/or polymers not being a problem.

Macrocycles 37 and $\mathbf{3 8}$ exhibit only weak coordinating ability towards silver tetrafluoroborate but none towards silver triflate or palladium(0). When macrocycles 37aaa, 37ggg, 38aaa, and 38aag were treated with $\mathrm{Cr}(\mathrm{CO})_{6}$ in refluxing di-n-butylether under inert atmosphere, extremely insoluble complexes were formed. Each of them showed two strong infrared peaks in the $1898 \pm 6$ and $1972 \pm 4 \mathrm{~cm}^{-1}$ regions, as required for trigonal-pyramidal complexes of the $\mathrm{L}_{3} \mathrm{Cr}(\mathrm{CO})_{3}$ type. Evidence for structures 37ggg- $\mathrm{Cr}(\mathrm{CO})_{3}$ and 38aag- $\mathbf{C r}(\mathbf{C O})_{3}$ was obtained by HRMS.

Finally we have taken advantage of the availability of intermediates $\mathbf{6}$ and $\mathbf{8}$, required for the formation of 15-membered macrocycles 1 through routes "a" and "b", for the preparation of 20membered macrocycles 46 (Scheme 13). ${ }^{22}$

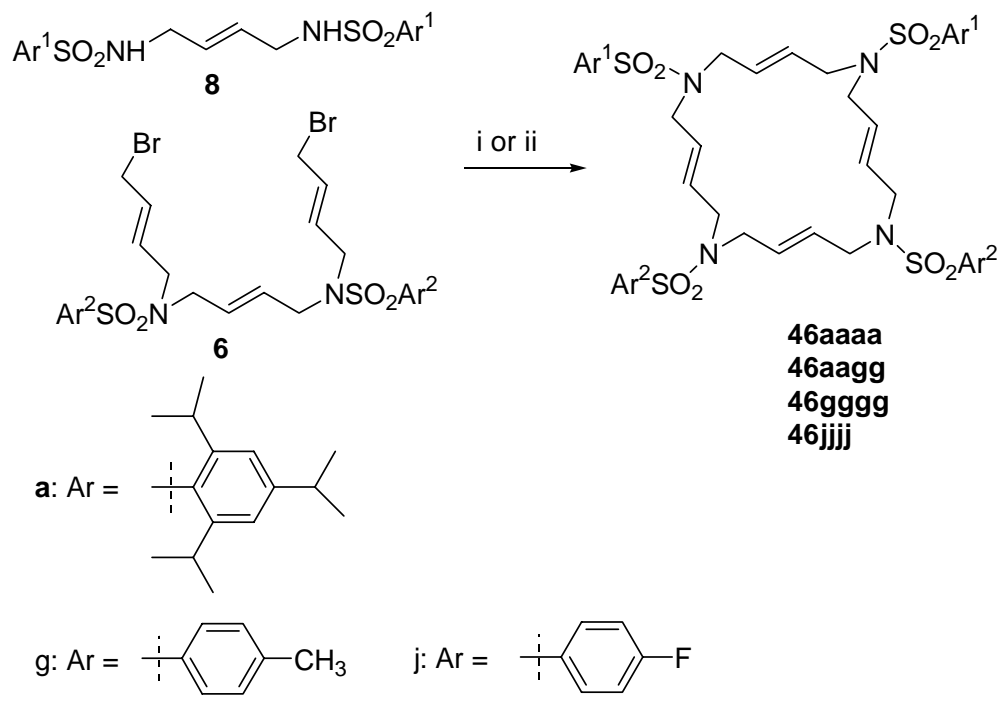

Scheme 13. Preparation of macrocycles 46. Reagents and conditions:

i.- $\mathrm{K}_{2} \mathrm{CO}_{3}$, refluxing $\mathrm{CH}_{3} \mathrm{CN}$; ii.- $\mathrm{NaH}$ on 8 , then 6 in $\mathrm{DMF}, 90^{\circ} \mathrm{C}$.

\section{Concluding remarks}

We have discovered a new family of 15-membered macrocycles easily made from commercially available trans-1,4-dibromo-2-butene and arenesulfonamides. The cyclization step is performed in good yield without special difficulties due to the formation of polymers or higher rings, although in certain cases both polymers and 30-membered rings have been detected or isolated. ${ }^{10}$ Macrocycles of this family coordinate certain transition metals. Thus, palladium(0), platinum(0), 
and silver(I) complexes have been prepared and analyzed. The palladium and platinum complexes are planar trigonal. Little is known on complexes with other transition metals.

The palladium complexes $\mathbf{4}$ are excellent catalysts or precatalysts in certain organic reactions traditionally catalyzed by palladium species. Thus, compounds $\mathbf{4}$ catalyze Suzuki-type cross couplings, ${ }^{6}$ Heck reactions, ${ }^{11}$ hydroarylation of alkynes, ${ }^{15}$ and telomerization of butadiene. ${ }^{8,14}$ The mechanisms of catalysis are different, and in some cases are far from clear. For telomerizations we have shown that complexes 4 play the role of palladium source before catalysis and harbor for palladium after catalysis, preventing agglomeration and precipitation. ${ }^{14}$ Recovery and reuse of our catalysts is possible in all the cases above referred, and even a polymeric version, amenable to recovery by simple filtration, has been successfully used. ${ }^{6}$ These facts permits us to believe that our palladium complexes of 15-membered macrocycles can be excellent substitutes for the more classical sources of palladium such as $\operatorname{Pd}_{2}(d b a)_{3}$ and $\operatorname{Pd}\left(\operatorname{PPh}_{3}\right)_{4}$. The traditional and broadly spread phosphine ligands have a serious drawback: they are strong reducing agents and, more frequently than not, they are converted into their phosphine oxides, thus permitting palladium to agglomerate and to precipitate in an inactive form.

Furthermore, the preparation of our ligands $\mathbf{1}$ is versatile. Only the olefinic double bonds are active as coordinating centers, the nitrogen atoms being non-coordinating. This permits to play with the sulfonamide moieties for different purposes. Thus, different substituents in the benzene ring, or other non-benzenic groups in the sulfonamide permit to enhance and improve certain properties to the macrocycles. This has been explained along the text of this review. Furthermore, we have opened a new axis of research in which we try to convert our macrocycles into molecular materials.

Finally, by varying the open-chain precursors, the synthesis of structurally related macrocycles is possible. Thus, preparations of its geometrical isomers, of compounds possessing benzene rings in the place of isolated double bonds, and of larger macrocycles such as 20membered rings have been performed.

\section{Acknowledgements}

Continuous financial support has been obtained from the Spanish Ministry of Science and Technology and from Generalitat de Catalunya. The last financed projects are 2002BQU-04002 and 2001SGR00181. Collaborations with the groups of Jacques Muzart and Françoise Hénin in Reims, and of Sandro Cacchi in Rome have been possible thanks to the COST program (COST D12/0011/98, D12/0028/999, and D24/0013/02) and to the Socrates-Erasmus program of the

European Union. One of us (R.M.S.) has been incorporated to the research group through a "Ramón y Cajal" contract (MCYT-FEDER/FSE). 


\section{References}

1. (a) Kaden, T.A. In Comprehensive Heterocyclic Chemistry, II; Katritzky, A.R.; Rees, C.W.; Scriven, E.F.V., Eds.; Elsevier Science Ltd: Oxford, 1996; Vol 9, Chapter 9.28, pp 789-807.

(b) Gokel, G.W.; Fedders, M.F., In ibid., Vol 9, Chapter 9.31, pp 863-892.

2. (a) Ripka, A.S.; Bohacek, R.S.; Rich, D.H. Bioorg. Med. Chem. Lett. 1998, 8, 357. (b) Goldring, W.P.D. Weiler, L. Org. Lett. 1999, 1, 1471.

3. For a review see: Wilke, G. Angew. Chem., Int. Ed. 1988, 27, 185.

4. Cerezo, S.; Cortés, J.; López-Romero, J.-M.; Moreno-Mañas, M.; Parella, T.; Pleixats, R.; Roglans, A. Tetrahedron 1998, 54, 14885.

5. Cerezo, S.; Cortés, J.; Galvan, D.; López-Romero, J.-M.; Moreno-Mañas, M.; Pleixats, R.; Avilés, F.X.; Canals, F; Roglans, A. Rapid Commun. Mass Spectrom. 1999, 13, 2359.

6. Cortés, J.; Moreno-Mañas, M.; Pleixats, R. Eur. J. Org. Chem. 2000, 239.

7. Cerezo, S.; Cortés, J.; Galvan, D.; Lago, E.; Marchi, C.; Molins, E.; Moreno-Mañas, M.; Pleixats, R.; Torrejón, J.; Vallribera, A. Eur. J. Org. Chem. 2001, 329.

8. Estrine, B.; Blanco, B.; Bouquillon, S.; Hénin, F.; Moreno-Mañas, M.; Muzart, J.; Pena, C.; Pleixats, R. Tetrahedron Lett. 2001, 42, 7055.

9. Llobet, A.; Masllorens, E.; Moreno-Mañas, M.; Pla-Quintana, A.; Rodríguez, M.; Roglans, A. Tetrahedron Lett. 2002, 43, 1425.

10. Moreno-Mañas, M.; Spengler, J. Tetrahedron 2002, 58, 7769.

11. Masllorens, J.; Moreno-Mañas, M.; Pla-Quintana, A.; Roglans, A. Org. Lett. 2003, 5, 1559.

12. Llobet, A.; Masllorens, E.; Rodríguez, M.; Roglans, A.; Benet-Buckholtz, J. Eur. J. Inorg. Chem. in press.

13. Cerezo, S.; Cortés, J.; Lago, E.; Molins, E.; Moreno-Mañas, M.; Parella, T.; Pleixats, R.; Torrejón, J.; Vallribera, A. Eur. J. Inorg. Chem. 2001, 1999.

14. Moreno-Mañas, M.; Pleixats, R.; Spengler, J.; Chevrin, C.; Estrine, B.; Bouquillon, S, Hénin, F.; Muzart, J.; Pla-Quintana, A.; Roglans, A. Eur. J. Org. Chem. 2003, 274.

15. Cacchi, S.; Fabrizi, G.; Goggiamani, A.; Moreno-Mañas, M.; Vallribera, A. Tetrahedron Lett. 2002, 43, 5537.

16. Keasey, A.; Mann, B.E.; Yates, A.; Maitlis, P.M. J. Organomet. Chem. 1978, 152, 117.

17. For recent reviews on the Suzuki cross-coupling see: (a) Suzuki, A. J. Organomet. Chem. 1999, 576, 147. (b) Kotha, S.; Lahiri, K., Kashinath, D. Tetrahedron 2002, 58, 9633.

18. For recent reviews on the Mizoroki-Heck reaction see: (a) Crisp, G.T. Chem. Soc. Rev. 1998, 27, 427. (b) Beletskaya, I.P.; Cheprakov, A.V. Chem. Rev. 2000, 100, 3009. (c) Whitcombe, N.J.; Hii, K.K.; Gibson, S.E. Tetrahedron 2001, 57, 7449. (d) Bhanage, B.M.; Arai, M. Catal. Rev. 2001, 43, 315.

19. For uses of ESI-MS in direct observation of reaction intermediates see: (a) Wilson, S.R.; Pérez, J.; Pasternak, A. J. Am. Chem. Soc. 1993, 115, 1994. (b) Aliprantis, A.O.; Canary, J.W. J. Am. Chem. Soc. 1994, 116, 6985. (c) Ripa, L.; Hallberg, A. J. Org. Chem. 1996, 61, 7147. (d) Brown, J.M.; Hii, K.K. Angew. Chem., Int. Ed. 1996, 35, 657. (e) Hii, K.K.; 
Claridge, T.D.W.; Brown, J.M.; Angew. Chem., Int. Ed. 1997, 36, 984. (f) Aramendía, M.A.; Lafont, F.; Moreno-Mañas, M.; Pleixats, R.; Roglans, A. J. Org. Chem. 1999, 64, 3592. (g) Griep-Raming, J.; Meyer, S.; Bruhn, T.; Metzger, J.O. Angew. Chem., Int. Ed. 2002, 41, 2738. In particular ref $19 \mathrm{c}-\mathrm{e}$ describe detection of intermediates in the Mizoroki-Heck reaction.

20. Cortès, J.; Moreno-Mañas, M.; Pleixats, R. Tetrahedron Lett. 2001, 42, 4337.

21. Sebastián, R.M.; Moreno-Mañas, M. ; Vallribera, A. Eur. J. Org. Chem. 2003, 3382.

22. Blanco, B.; Cerezo, S.; Moreno-Mañas, M.; Pleixats, R.; Spengler, J. Tetrahedron Lett. 2001, 42, 9001. 